\title{
Ameliorative effects of melatonin on the liver of pregnant albino rats and their offspring induced by monosodium glutamate
}

\author{
Abd El-Fattah BM El-Beltagy \\ Zoology Department, Faculty of Science, Damanhour University, Damanhour, Egypt
}

\section{Article history}

Received: 24 Feb, 2016

Revised: 28 Mar, 2016

Accepted: 31 Mar, 2016

\begin{abstract}
Monosodium glutamate (MSG) is one of the most widely used food additives as a flavour enhancer but its high dose can induce toxic effects on the liver. Melatonin is a potent antioxidant, could ameliorate acute and chronic hepatic injury. The present work was essentially designed to evaluate the ameliorating role of melatonin on the liver of pregnant female Albino rats and their pups induced by MSG. In the present research, twenty four pregnant Albino rats were divided into four groups $(n=6)$. The control group received saline solution, the melatonin group received $100 \mathrm{mg} / \mathrm{kg} \mathrm{b.wt}$, MSG treated group received $400 \mathrm{mg} / \mathrm{kg}$ b.wt and ameliorative group received MSG $400 \mathrm{mg} / \mathrm{kg}$ b.wt simultaneously with melatonin $100 \mathrm{mg} / \mathrm{kg} \mathrm{b.wt.} \mathrm{All} \mathrm{groups} \mathrm{were}$ received their corresponding dose from the $4^{\text {th }}$ day of gestation till the end of weaning period. The histological study of the current work revealed that MSG could induce damage of hepatocytes with cytoplasmic vacuolation, dilation of central vein and blood sinusoids, prominent Kupffer cells, infiltration cells around the portal area, variable degree of fibrosis, and scattered fatty cells. Furthermore, MSG consumption is also associated with ultrastructural alterations that varied considerably from mild structural changes to cytoplasmic lysis and degradation of some cellular organelles. Such alterations were represented by undifferentiated cytoplasm with dispersed vacuoles, nuclear pyknosis, swollen and vacuolated mitochondria, manifested dilated rough endoplasmic reticulum, remarkable aggregation of glycogen granules and fat droplets and obvious dispersion of collagenous fibers. Supplementation of melatonin ameliorated MSG-induced histopathological and ultrastrucural changes in liver cells. Keywords: MSG, Liver, Melatonin, Histopathlology, Fibrosis, TEM, Hepatocytes
\end{abstract}

\footnotetext{
To cite this article: Abd El-Fattah BM El-Beltagy, 2016. Ameliorative effects of melatonin on the liver of pregnant albino rats and their offspring induced by monosodium glutamate. Res. Opin. Anim. Vet. Sci., 6(2): 5968.
}

\section{Introduction}

Monosodium glutamate (MSG) is a flavorenhancing food additive that is used in fast foods and some commercially packaged food products (Walker and Lupien, 2000). MSG is derived from glutamic amino acid that is found naturally in some kinds of foods like mushrooms, fish, meat, milk, cheese and tomato. Recently, MSG synthesized in commercial commodities by bacterial fermentation (Leung and Foster, 2003). MSG contains 78\% of glutamic acid, $22 \%$ of water and sodium (Samuels, 1999). Glutamic

*Corresponding author: Abd El-Fattah BM El-Beltagy, Zoology Department, Faculty of Science, Damanhour University, Damanhour, Egypt; E-mail: beltagyaaa@yahoo.com 
acid belongs to glutamates, which are the main source of a flavor known as umami (Kobayashi et al., 2006). The liver is the main site for metabolism of glutamate into lactate and the kidney plays a role in its excretion. Furthermore, some MSG is converted into alanine in the mucosal cells of the intestine (Garattiini, 2000).

Later studies by Geha et al. (2000) indicated that MSG may cause symptoms such as weakness, headaches, numbness, sweating, flushing, dizziness, ventricular arrhythmia, neuropathy and abdominal discomfort. It had been found that, the exposure of neonatal rats to high doses of MSG may cause steatohepatitis and evidence of pre-neoplastic changes in the liver (Nakanishi et al., 2008). Recent studies revealed that ingestion of MSG is a main cause for increasing the relative weight of both liver and kidney. Furthermore, MSG may elevate the level of both liver and renal functions (Tawfik and Al-Badr, 2012). Moreover, MSG could induce male infertility through testicular hemorrhage, oligospermia and morphological abnormalities of sperm cell populations (Oforofuo et al., 1997; Onakewhor et al., 1998). Multiple necrotic, necrobiotic and degenerative changes had been noticed in the pancreatic cells as a result of chronic exposure to low-dose of MSG (Falalyeyeva et al., 2012). Several studies found that the daily dietary consumption of glutamate varies from one race to another, where daily oral amount ranges from $0.5 \mathrm{mg} / \mathrm{kg}$ amongst Americans and over $3 \mathrm{~g} / \mathrm{kg}$ in Taiwanese diets (Zhou et al., 2003; He et al., 2008; Shi et al., 2010).

Melatonin (N-acetyl-5-methoxytryptamine) is a powerful endogenous antioxidant hormone secreted from the pineal gland. In vitro application of melatonin leads to a remarkable reduction in oxidative stress and inflammation because of its ability to remove hydroxyl radicals and cytokines (Tahan et al., $2004 \&$ 2009). Also, several studies revealed that melatonin has an indirect antioxidant action by stimulating the ratios of potential antioxidants such as glutathione peroxidase (GPx), glutathione (GSH) and superoxide dismutase (SOD), (Sener-Muratoğlu et al., 2001; Rozov et al., 2003; Tahan et al., 2004). Furthermore, melatonin inhibits the proliferation of fibroblasts and collagen synthesis (Tahan et al., 2004; Cruz, 2005). Recent studies revealed that melatonin plays an essential role in the amelioration of liver fibrosis (Hong et al., 2009; Tahan et al., 2009; Alabbassi, 2010). Moreover, melatonin can attenuate the chronic and acute liver injury (Saad et al, 2013). Further, melatonin has a protective role against haemolysis of red blood cells (Rao et al., 2011) and prevents chemically treated haemopoietic cell death (Salucci et al., 2014). Melatonin protects the kidneys, heart and lungs from oxidative stress (Farías et al., 2012). Also, melatonin appears to improve renal damage (Yenilmez et al., 2010); the cerebral damage (Jayanthi et al., 2009) and amelioration of irradiation-induced testicular damage (Take et al. (2009).
The recent study was aimed to investigate the ameliorating role of melatonin on the MSG treated liver of female rats and their offspring.

\section{Materials and Methods}

Chemicals: MSG and melatonin were purchased from Sigma Company in Mansoura city, Egypt.

\section{Experimental groups}

Twenty four healthy females and eight males Albino rats (2-3 months old) were used in the present work. Their weights ranged from 200-250 gm. They were maintained under standard laboratory conditions that is a well aerated room with alternating light and dark cycles of 12 hours each and at room temperature of $25^{\circ} \mathrm{C}$. All rules applying to animal safety and care were observed. The mating was done between males and females by the ratio 1:3. After pregnancy, the females were separated and divided into four groups.

Group I: (control group) Include six female pregnant Albino rats receiving daily intraperitoneal (IP) injections of normal saline solution.

Group II: Include six female pregnant rats that were given a daily I.P dose of melatonin $(100 \mathrm{mg} / \mathrm{kg}$ body weight) diluted with $0.9 \% \mathrm{NaCl}$. The dose was selected according to Tahan et al. (2010).

Group III: Included six female pregnant rats that were given a daily oral dose of MSG $(450 \mathrm{mg} / \mathrm{kg}$. body weight). The dose was chosen according to Diniz et al. (2004) and Waer and Edress (2006).

Group IV: Include six female pregnant rats that were given oral dose of MSG at the rate of $450 \mathrm{mg} / \mathrm{kg}$ body weight) simultaneously with I.P dose of melatonin (100 $\mathrm{mg} / \mathrm{kg}$ body weight).

All groups were given the corresponding dose through the period from the $4^{\text {th }}$ day of pregnancy until the end of the weaning period ( $21^{\text {th }}$ day of birth). The embryos of all groups were separated at 7, 14 and 21 days, then sacrificed and rapidly dissected to obtain the liver. Also, the mothers of all groups were sacrificed at $21^{\text {th }}$ day of birth and the liver was removed. The liver specimens of embryos and mothers were divided into two parts for under bright field Leitz microscope (Essette Leitz GmbH \& Co KG, Germany) and a Joel $100 \mathrm{CX}$ transmission electron microscope (Musashino 3-chome; Akishima, Tokyo, Japan).

\section{Preparation for light microscope}

Liver specimens of both control and treated groups were fixed in $10 \%$ neutral buffered formalin solution for 24-48 hours. The tissues were then dehydrated in an ascending series of alcohol solution. After that, the tissues were cleared by two changes of xylene for one hour each, and finally embedded in melting paraffin 
wax and prepared for sectioning under microtome. The 5-6 $\mu \mathrm{m}$ thick section were obtained, stained with haematoxylin and eosin, and other sections were subjected to Masson's trichrome stain (Mc Manus and Mowry, 1963) .

\section{Preparation for electron microscopy}

In our study, the transmission electron microscopic examination was focused only on 21 days old rats and their mothers in groups I, III and IV. The liver specimens were cut into smaller blocks less than $1 \mathrm{~mm}^{3}$. They were fixed for 5 hours in 5\% glutraldehyde buffered at $\mathrm{pH} \quad 7.3$ with 0.1 micron Sorensen's phosphate buffer at $4^{\circ} \mathrm{C}$. The specimens were washed in $5 \%$ sucrose of $0.1 \mathrm{~m}$ phosphate buffer $(\mathrm{pH} 7.3)$ (Hayat, 1970). The tissue was then post-fixed for 2 hours in $1 \%$ osmium tetroxide, then washed twice for 15 minutes in a phosphate buffer ( $\mathrm{pH}$ 7.3), dehydrated through a graded ethanol to propylene oxide and embedded in Araldite. Semithin sections of 0.7-0.8 $\mu \mathrm{m}$ thick were cut with glass knives on the 6000 MT RMC ultramicrotome, then stained with $0.25 \%$ toluidine blue and examined by light microscope for proper orientation. Thin sections $\left(600-700 \mathrm{~A}^{0}\right)$ were then cut and collected on copper grids. These sections were stained in aqueous uranyl acetate and lead citrate and then examined and photographed in a JEOL 1200 EXIL transmission electron microscope.

\section{Results}

\section{Histological Observations:}

\section{Examination of liver sections stained with}

Hematoxylin and eosin (H\&E)

Group I (control) and Group II (melatonin): In the control and melatonin treated groups, the liver sections of mother rats (Fig. 1A\&B) and their offspring (Figs. 2$4 A \& B$ ) exhibited a normal histological architecture. The hepatic lobules appeared regular and separated from each other by connective tissues. Each hepatic lobule consisted of hepatic strands radiating from a central vein and separated by blood sinusoids. In mothers, the blood sinusoids appeared narrower than those of the offspring. Blood sinusoids are lined with endothelial and few Kupffer cells. The hepatic lobules are interconnected by the portal areas which represented by a branch of the hepatic vein, a branch of the hepatic artery and bile ductule. The hepatocytes are polyhedral in shape with rounded centrally located nuclei.

Group III (MSG treated group): The examined liver sections of MSG treated mothers rats (Fig.1C \& $\mathrm{C}^{*}$ ) showed excessive numbers of damaged hepatocytes that have lost their characteristic appearance with excess fatty degeneration spots. Moreover, inflammatory leukocytes infiltration, activated Kupffer cells, dilated central vein and blood sinusoids with markedly haemorrhage areas were recorded in several sections.

The liver sections of 7 day's old rats showed moderate disturbances in liver architecture, including necrotic areas, mild vacuolation, dilated blood sinusoids and congested central vein with partially ruptured endothelial lining and little infiltration cells (Fig.

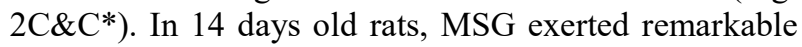
effects on liver sections which were represented by multiple necrotic and pyknotic areas, damaged hepatocytes, and active Kupffer cells around dilated blood sinusoids. The endothelial lining of central

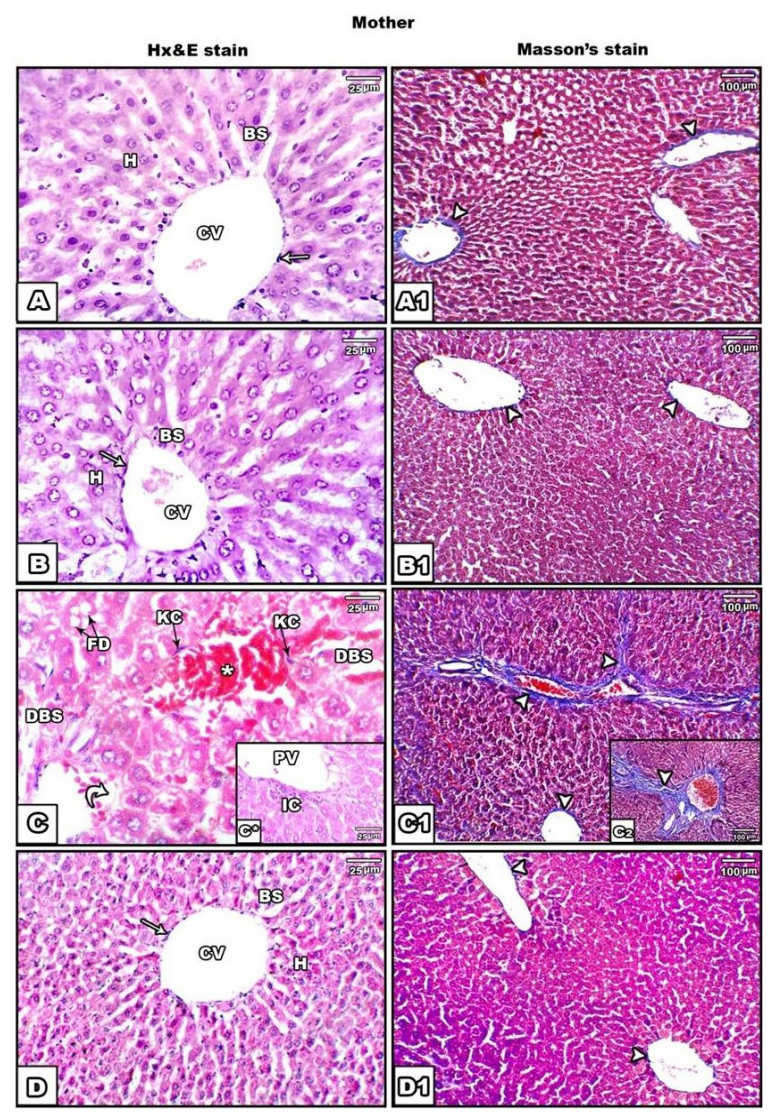

Fig. 1: Photomicrographs of histological sections of liver of mothers rats. A-B1: liver sections of control (A-A1) and melatonin treated (B-B1) mothers rats showing normal histological appearance of the liver, including central vein (CV) with intact endothelium (arrow), blood sinusoids (BS), hepatocytes $(\mathrm{H})$, and thin layer of collagenous fibers (arrow head) around the central and portal veins. C-C1 liver sections of MSG treated mothers rats showing dilated blood sinusoid (DBS) with ruptured endothelium (curved arrow) and haemorrhagic areas (star), infiltrated cells (IC) around the portal vein (PV), active Kupffer cells (KC) and thick layer of connective tissue fibers (arrow head) in between the hepatic lobules and portal triad. D-D1: liver sections of MSG treated mothers rats supplemented with melatonin showing demonstrated restoration of normal arrangement of hepatocytes, although dilatation in blood sinusoids (DBS). 


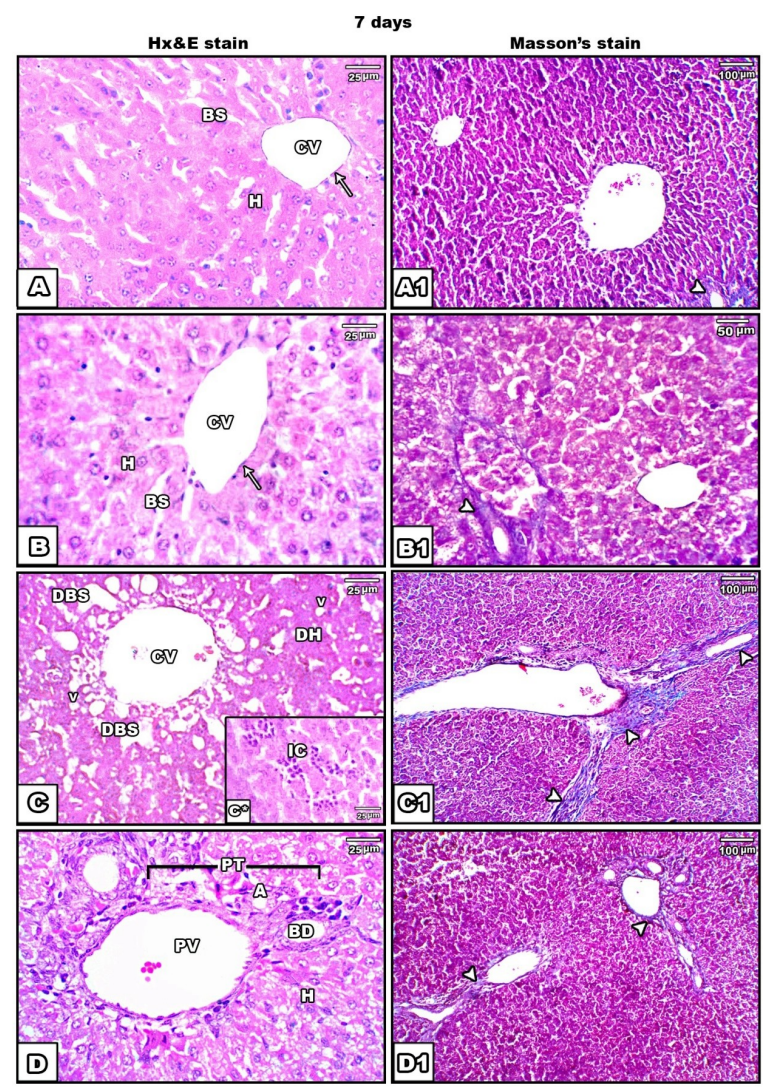

Fig. 2: Photomicrographs of histological sections of liver of 7 days old rats. A-B1: liver sections of control (A-A1) and melatonin treated (B-B1) 7 days old rats showing normal histological architecture of the liver with relatively dilated blood sinusoids in comparing with mothers. C-C2: liver sections of MSG treated 7 days old rats showing damaged hepatocytes (DH), cytoplasmic vacuoles (V), dilated blood sinusoid (DBS) with ruptured endothelium (curved arrow), infiltrated cells (IC) in blood sinusoids and thick layer of connective tissue fibers (arrow head) around portal triad. D-D1: liver sections of MSG treated 7 days old rats supplemented with melatonin showing demonstrated restoration of normal arrangement of hepatocytes and potal triad (PT).

vein appeared fragmented. Also, a congested portal vein was recorded (Fig. $3 \mathrm{C} \& \mathrm{C}^{*}$ ). Furthermore, the liver sections of 21 days old rats showed severe histological alteration similar to that of mothers. Such alterations were represented by remarkable pyknotic and necrotic area, fatty degeneration spots, dilated blood sinusoids with haemorrhagic areas and active Kupffer cells. The wall of portal vein appeared fragmented and in continuity with several blood sinusoids. (Fig. 4C\&C*).

\section{Group IV (MSG supplemented with melatonin)}

In mother's rats, the liver sections showed obvious improvement in their architecture, including normal arrangement of hepatic strands, the intact endothelium of central vein in spite of little cytoplasmic vacuoles was still observed (Fig. 1D). At 7 days old rats, the liver

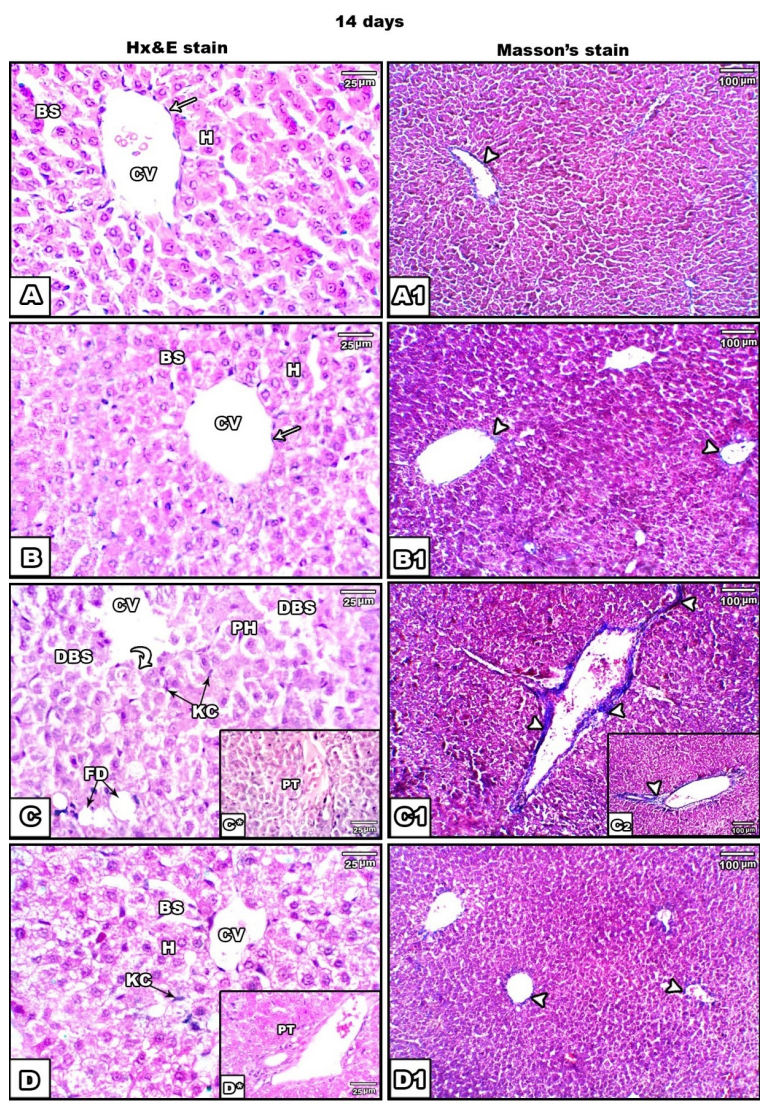

Fig. 3: Photomicrographs of histological sections of liver of 14 days old rats. A-B1: liver sections of control (A-A1) and melatonin treated (B-B1) 14 days old rats showing normal histological architecture of the liver. C-C1 liver sections of MSG treated 14 days old rats showing pyknotic hepatocytes $(\mathrm{PH})$, activated Kupffer cells (KC), fatty degeneration (FD), congested portal triad (PT in $\mathrm{C}^{*}$ ) and relatively thick layer of branched collagenous fibers (arrow heads) around the portal triad. D-D1: liver sections of MSG treated 14 days old rats supplemented with melatonin showing demonstrated amelioration of normal arrangement of hepatocytes and portal triad (PT) in spite of few vacuoles still persist around the portal vein.

sections showed preserved architecture with mild vacuolation of hepatocytes and slightly congested portal area (Fig. 2D). In the 14 days old rats, the liver sections revealed a remarkable preservation of liver structures with mild dilation of blood sinusoids and little vacuolation still persisted but the portal triad appeared regular (Fig. 3D\&D*). In 21 days old rats, the degree of amelioration was better than in the other two groups of ages in offspring where the liver sections exhibited normal hepatocytes with regular vascular areas (Fig. 4D).

\section{Examination of liver sections stained with Masson's trichromate}

In control and melatonin treated groups, the liver sections of mother's rats (Fig. A1\&B1) and their offspring (Fig. 2-4 A1\&B1) showed normal distribution 


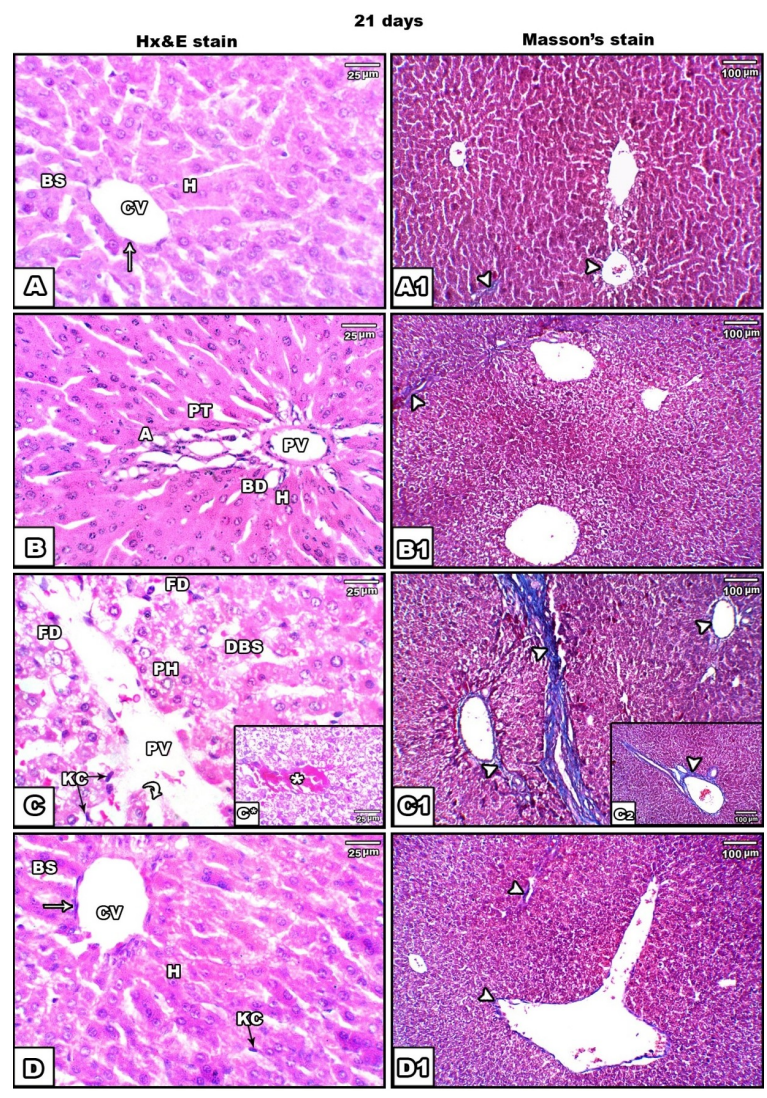

Fig. 4: Photomicrographs of histological sections of liver of 21 days old rats. A-B1: Liver sections of control (A-A1) and melatonin treated (B-B1) 21 days old rats showing normal histological structure of the liver. C-C2: Liver sections of MSG treated 21days old rats showing pyknotic hepatocytes $(\mathrm{PH})$, activated Kupffer cells (KC), fatty degeneration (FD), congested blood sinusoids (star) and thick layer of branched collagenous fibers (arrow heads) around the portal vein and between the hepatic lobules. D-D1: liver sections of MSG treated 21days old rats supplemented with melatonin showing marked amelioration of the normal arrangement of hepatocytes and central vein (CV).

of thin layer of collagenous fibers around the central vein and portal areas. The fibrous connective tissue was not found in or around the hepatic lobules.

In MSG treated group, the liver sections of mothers rats exhibited a marked increase of connective tissue fibers in the portal area as well as around the hepatic lobules (Fig. $1 \mathrm{C} 1 \& \mathrm{C} 2$ ). On the other side, the liver sections of 7 days old rats (Fig. $2 \mathrm{C} 1$ ) and 14 days old rats (Fig. $3 \mathrm{C} 1 \& \mathrm{C} 2$ ) showed a moderate distribution of collagenous fibers around the portal area. Furthermore, the liver sections of 21 days old rats exhibited severe fibrotic areas around the portal triads and in-between hepatic lobules (Fig. $4 \mathrm{C} 1 \& \mathrm{C} 2$ ).

In MSG and melatonin supplemented group the degree of liver fibrosis was markedly reduced in variable levels among the mothers and their studied ages. In the mother rats (Fig. 1D1) and their 21 days old

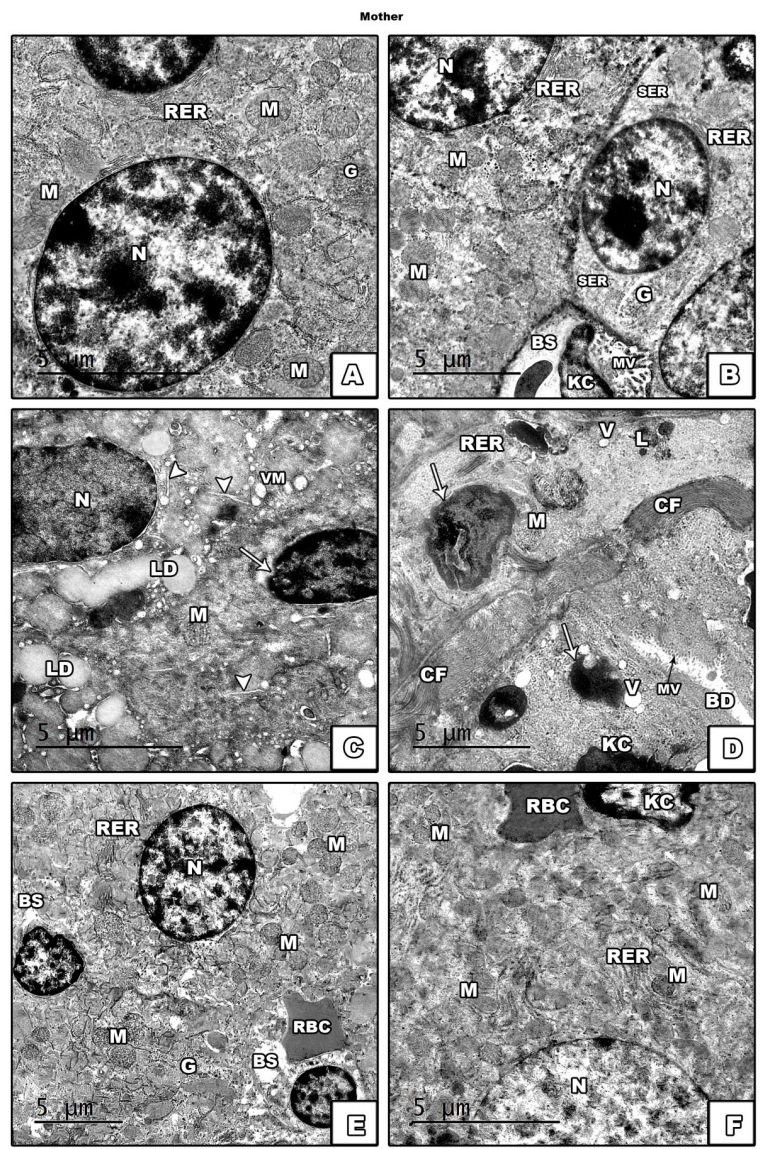

Fig. 5: TEM through the liver cells of mother rats. A-B: Control liver cells showing rounded or oval nucleus $(\mathrm{N})$, high density of oval or rounded mitochondria (M), regular rough endoplasmic reticulum (RER), and regular microvilli (MV) of bile canaliculus.C-D:MSG treated liver cells showing pyknotic nuclei(arrow), cytoplasmic vacuoles (V), vacuolated mitochondria (VM), dilated rough endoplasmic reticulum (arrow head),scattered lipid droplets(LD) and collagenous fibers (CF). E-F: MSG treated liver cells supplemented with melatonin showing obvious amelioration of fine structure of hepatocytes.

offspring (Fig. 4 D1), the liver sections exhibited mild fibrotic areas around the portal vein. On the other side, the liver sections of 7 days old rats (Fig. 2 D1) and 14 days old rats (Fig. 3 D1) showed a thin layer of collagenous fibers around the portal area which more or less similar to the control group.

\section{Ultrastructural observations} in group I (control group):

TEM examination of the control liver of mother rats (Fig. $5 \mathrm{~A} \& \mathrm{~B}$ ) and 21 days old rats (Fig. 6 A\&B) revealed that each hepatocyte exhibits a round or oval, centrally located nucleus enclosed by regular double membrane interrupted by nuclear pores; the nucleus possessed light euchromatin and dark heterochromatin. The cytoplasm of the hepatocytes displayed high 


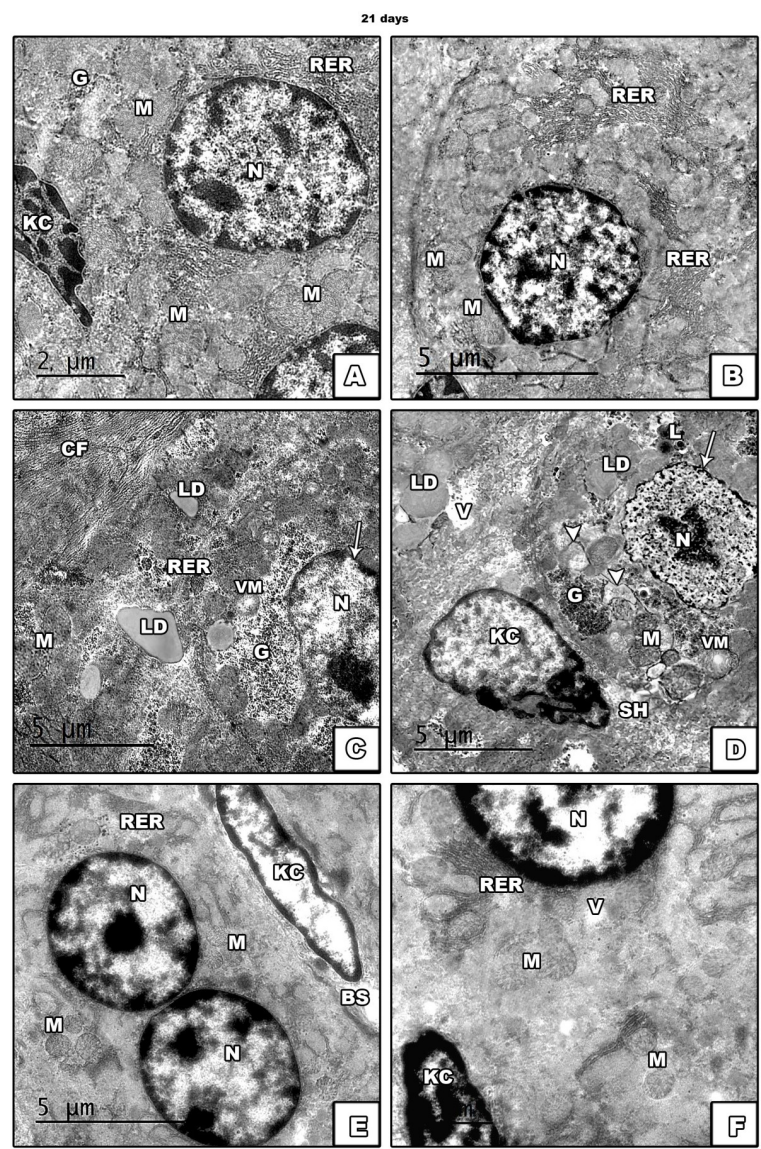

Fig. 6: TEM through the liver cells of 21 days old rats. AB: Control liver cells showing rounded nucleus $(N)$, few oval or rounded mitochondria $(\mathrm{M})$, distinctive rough endoplasmic reticulum (RER), few glycogen granules (G), C-D: MSG treated liver cells showing pyknotic nuclei (arrow), cytoplasmic vacuoles (V), vacuolated mitochondria (VM), dilated rough endoplasmic reticulum (arrow head), scattered lipid droplets (LD) and collagenous fibers (CF), Kupffer cells with narrow space of His (SH). E-F: MSG treated liver cells supplemented with melatonin showing obvious amelioration of fine structure of hepatocytes in spite of few cytoplasmic vacuoles still persist.

density of mitochondria, scarce lysosomes, distinctive rough endoplasmic reticulum, and few dispersed glycogen granules.

\section{Group III (MSG treated group)}

TEM examination of the liver cells of group III revealed remarkable ultrastructural alterations that varied considerably from mild structural changes to cytoplasmic lysis and signs for disintegration of some cellular organelles. In MSG treated mother's rats dispersed fibrotic areas were appeared. The microvilli of bile canaliculi appeared fragmented. Active Kupffer cells were obviously noticed around the area of blood sinusoids. The cytoplasm of liver cells appeared undifferentiated with dispersed vacuoles and increased aggregation of glycogen granules and fat droplets. Moreover, elongated electron dense mitochondria, dilated rough endoplasmic reticulum were obviously observed. Also severe pyknotic nuclei with irregular nuclear membrane were also recorded in several hepatic cells (Fig. $5 \mathrm{C} \& D$ ). In 21 days old rats, the nuclei of some hepatocytes showed pyknosis, other nuclei were round or ovoid with peripheral heterochromatin. Some mitochondria appeared swollen and vacuolated with degenerated cristae. Moreover, manifested dilated endoplasmic reticulum, remarkable fat droplets, vacuolation and active Kupffer cells were also noticed (Fig. 6 C\&D).

\section{Group IV (MSG supplemented with melatonin):}

TEM examination of liver of group IV revealed obvious amelioration of hepatocytes. The degree of improvement was more obvious in the liver cells of the offspring rather than their mothers. The liver cells of mother's rats showed a high density of normal mitochondria with their regular pattern of cristea. The rough endoplasmic reticulum almost maintained their normal appearance. The distribution of glycogen granules and fatty droplets appeared homogenous, although some hepatocytes still have few vacuoles. The nuclei appeared oval with normal chromatin in spite of mild pyknosis still persist in few nuclei. Also, few Kuffer cells were noticed (Fig. 5E\&F). Moreover, at 21 days old rats the hepatocyte manifested homogenate cytoplasm with normal distribution of glycogen granules and lipid droplets. The mitochondria appeared normal with regular cristea in spite of few mitochondria still swollen in some areas. The rough endoplasmic reticulum appeared regular with normal spaces between their tubes. The nuclei appeared oval or rounded with uniform distribution of chromatin and prominent nucleoli (Fig. 6 E\&F).

\section{Discussion}

Recently MSG gained popularity as a taste enhancer but at the same time doubts were increased about MSG as a causative agent of Chinese restaurant syndrome (Neurotoxic effects on brain, obesity and metabolic defects). A great danger is hidden in an increased use of MSG (Bojanić et al., 2009). Many studies have indicated that the application of high doses of MSG to experimental animals may cause lesions of neural structures, the retina, and a series of neuroendocrine disorders, infertility and fatty liver. MSG was shown to penetrate the placental barrier and to distribute to embryonic tissues (Frieder and Grimm, 1984; Yu et al., 1997). The results of the present work revealed that oral administration of MSG to the pregnant and lactating mother rats causes multiple changes in the histological structure of the liver for both mothers and 
their offspring, such observations were in accordance with Frieder and Grimm (1984) and Yu et al. (1997). Our results indicated that the degree of liver histopathology induced by MSG depends upon the time of exposure. Accordingly, the degree of liver histological alterations was mild for a one week old rats in comparing with the other higher ages. Moreover, for one week and two weeks old rats, such histological alterations were ranged between necrotic areas, vacuolation, dilated and congested central vein with partially ruptured endothelial lining and damaged hepatocytes as well as active Kupffer cells. Our observations go parallel with the findings of Eweka et al. (2011) who reported disruption of liver architecture and evidence of hepatocyte degradation and hypertrophy as a response of oral MSG in rat offspring. They also noted mild haemolysed RBCs in central vein and haemorrhagic necrosis in centrilobular is similar to ours. Furthermore, Bhattacharya et al. (2011) found that exposure of neo-natal Albino mice to MSG leads to disruption of cell membranes of hepatocytes, dilation of portal vein and blood sinusoids and activation of Kupffer cells. Moreover, the present study revealed that in 21 days old rats and their mothers, severe histopathological changes were noticed in most of liver sections. Such changes were represented by excessive damaged hepatocytes with excess fatty degeneration spots and glycogen accumulation. Moreover, inflammatory leukocyte infiltration, activated Kupffer cells, dilated central vein and blood sinusoids were markedly recorded. These results were accordance with those reported by Diniz et al. (2004) who found that administration of MSG was associated with oxidative stress in hepatic tissues, leading to increased glycogen content of liver cells as a result of hyperglycemia and hyperinsulinemia. Malik and Ahluwalia (1994) reported that subcutaneous administration of MSG to adult mice (dose level over $4 \mathrm{mg} / \mathrm{g}$ b.wt.) caused a significant increase in the content of liver glycogen, total lipids, phospholipids, free fatty acids and triglycerides. Furthermore, the results concerning disturbed liver structure go parallel with the findings of Waer and Edress (2006) who revealed that MSG treated rats showed remarkable alterations in the liver histological architecture; haemorrhage in central veins, areas of necrosis, vaculation and increased inflammatory cells infiltration.

Melatonin is a secretory product of the pineal gland is a powerful endogenous antioxidant. Exogenous application of this melatonin leads to a remarkable decline in oxidative stress and inflammation because of its ability to scavenge hydroxyl radicals and cytokines (Tahan et al., 2004, 2009). The results of the present work revealed that, supplementation of melatonin in mother's rats can improve the deleterious effects of MSG on the liver architecture. The degree of hepato- protective effects of melatonin was more obvious in the 21 days old rats and their mothers than in 7 and 14 days old rats. This observation may be due to the cumulative effect of melatonin from the beginning of pregnancy till the end of weaning period. Such ameliorations were represented by preserving liver architecture with mild vacuolation of hepatocytes and slightly congested central vein in 7 days old rats and a remarkable preservation of liver structures with mild dilation of blood sinusoids and little vacuolation in 14 days old rats. In 21 days old rats and their mothers, a remarkable arrangement of hepatic strands and portal areas were recorded in examined liver sections in spite of little vacuolation and few dispersed glycogen granules and fatty droplets were noticed in some area. Saad et al. (2013) found that melatonin can reduce the liver injury of rats through inhibition of oxidative stress and activation of antioxidants.

The present study revealed that MSG caused liver fibrosis by accumulation of collagenous fibers around the portal area and among hepatocytes. The density of collagenous fibers was highly remarkable in the liver sections of 21days old rats and their mothers than in 7 days and 14 days old rats. Such observation goes parallel with finding of Waer and Edress (2006) who was reported that the degree of liver fibrosis induced by MSG depends upon the dose and cumulative effect by increased the time of exposure. Many studies revealed that, taurine (derivative of the amino acid cysteine, obtained from the bile of animals) can inhibit the cellular disorders by decreasing the oxidative stress and had a protective role against substances that induce liver fibrosis (Wingenfeld et al., 1996; You and Chang, 1998; Hardikar et al., 2001; Waer and Edress, 2006). Furthermore, Messina and Dawson (2000) mentioned that, MSG could be decreased the taurine level and consequently induce the accumulation of collagen fibers in the liver cells (Chen et al., 1999).

In the recent study, administration of melatonin ameliorated the fibrotic effects induced by MSG. The results of the present work were in line with that of Tahan et al. (2010) who found that melatonin ameliorates liver fibrosis induced by bile-duct ligation in rats via the mechanism involving a decrease of proinflammatory cytokines (IL-1 $\beta$, IL- 6 and TNF- $\alpha$ ) levels. Several studies suggested that melatonin has either a regulatory role in maintaining collagen levels or an inhibitory role in collagen accumulation by inhibition of oxidative stress (Cunnane et al., 1979; Drobnik and Dabrowski, 1996; Tahan et al., 2004).

In the present work, the TEM study revealed that in MSG treated group, a remarkable cellular alterations were appeared, and such alterations were varied from mild structural alterations to cytoplasmic lysis and disruption of cellular organelles. In 21 days old rats, the recorded alterations were represented by nuclear 
pyknosis, swollen mitochondria with degenerated cristae, dilated rough endoplasmic reticulum, remarkable fat droplets and cytoplasmic vacuolation. Similar results were found in the liver of Albino rats that received MSG for 8 weeks (ElAgouza et al., 2010). Furthermore, the same ultrastructural changes were recorded in the liver cells of MSG treated mothers in addition to obvious dispersed fibrotic areas, fragmented microvilli of bile canaliculi and increased aggregation of glycogen granules. Mohareb and Hamza (2001) found that MSG caused nuclear pyknosis, tissue necrosis and fibrosis, disruption of plasma membranes and swelling of most cell organelles followed by their fragmentation. Many studies evaluated that melatonin can reduce the cellular disorders of liver by decreasing the oxidative stress, and had a protective effect against drugs that induce harmful cellular alterations ( $\mathrm{Pal}$ and Chatteriee, 2006; Koksal et al., 2012).

\section{Conclusion}

Based on our findings, consumption of MSG during pregnancy and weaning period leads to various degrees of liver injury for mothers and their offspring. Melatonin could be a potential therapeutic agent against chronic and acute liver injuries induced by MSG. Also melatonin could be a powerful agent for the treatment of fibrotic liver diseases.

\section{References}

Al-abbassi MG (2010) Melatonin Ameliorates Hepatic Damage Induced by Cyclophosphamide in Rats. AL-TAQANI J 23: 1-7.

Bhattacharya T, Bhakta A, Ghosh SK (2011) Long term effect of monosodium glutamate in liver of albino mice after Neo-natal exposure. Nepal Med Coll J 13: 11-16.

BojanićV, Bojanić Z, Najman S, Savić T, Jakovljević V, Najman S, Jancić S (2009) Diltiazem prevention of toxic effects of monosodium glutamate on ovaries in rats. Gen Physiol Biophys 28: 149-154.

Chen Y, Li S, Zhang X (1999) Taurine inhibits deposition of extracellular matrix in experimental liver fibrosis Zhonghua Gan Zang 7: 165-7.

Cruz A, Padillo FJ, Torres E, Navarrete CM, MuñozCastañeda JR, Caballero FJ, Briceño J, Marchal T, Túnez I, Montilla P, Pera C, Muntané J (2005) Melatonin prevents experimental liver cirrhosis induced by thioacetamide inrats. J Pineal Res 39: 143-150.

Cunnane SC, Manku MS, Horrobin DF (1979) The pineal and regulation of fibrosis: pinealectomy as a model of primary biliary cirrhosis: roles of melatonin and prostaglandins in fibrosis and regulation of $\mathrm{T}$ lymphocytes. Med Hypotheses 5: 403-14.
Diniz YS, Fernandes AAH, Campos KE, Mani F, Ribas BO, Novelli, EB (2004) Toxicity of hypercaloric diet and monosodium glutamate: oxidative stress and metabolic shifting in hepatic tissue. Food Chem. Toxicol 42: 313-319.

Drobnik J, Dabrowski R (1996) Melatonin suppresses the pinealectomy induced elevation of collagen content in a wound. Cytobios 85: 51-8.

ElAgouza IMA, El Nashar DE, Eissa SS (2010) The Possible Ultra Structural Ameliorative Effect of Taurine in Rat's Liver Treated with Monosodium Glutamate (MSG). Open Hepato J 2: 1-9.

Eweka A, Igbigbi P, Ucheya R (2011) Histochemical studies of the effects of Monosodium glutamate on the liver of wistar rats. Ann Med Health Sci Res 1: 21-9.

Falalyeyeva TM, Leschenko IV, Shevchuk VO, Beregova TV (2012) About the influence of longterm injection of monosodium glutamate on pancreas in rats. Euro J Clin Investig 42(s1):5

Farías JG, Zepeda AB, Calaf GM (2012) Melatonin Protects the Heart, Lungs and Kidneys from Oxidative Stress under Intermittent Hypobaric Hypoxia in Rats Biol Res 45: 81-85.

Frieder B, Grimm VE (1984) Prenatal Monosodium Glutamate (MSG) Treatment Given Through the Mother's Diet Causes Behavioral Deficits in Rat Offspring. Int J Neurosci 23: 117-26.

Garattiini S (2000) Glutamic Acid, Twenty Years Later. J Nutr 130: 9018-98.

Geha RS, Beiser A, Ren C, Patterson R, Gra- mmar LC, Ditto AM, Harris KE (2000) Multicenter, doubleblind, placebo-controlled, multiple-challenge evaluation of reported reactions to monosodium glutamate. J Allergy Clin Immunol 106: 973-80.

Hardikar AA, Risbud MV, Remacle C, Reusens B, Hoet JJ, Bhonde RR (2001) Islet cryopreservation: improved recovery following taurine pretreatment. Cell Transplant 10: 247-53.

Hayat M (1970) Principles and techniques of Electron Microscopy. Harper and Row, New York. 1st ed, 343.

He K, Zhao L, Daviglus ML, Dyer AR, Van Horn L, Garside D, Zhu L, Guo D, Wu Y, Zhou B, Stamler J (2008) Association of monosodium glutamate intake with overweight in Chineseadults: the INTERMAP Study. Obesity 16: 1875-1880.

Hong RT, Xu JM, Mei Q (2009) Melatonin ameliorates experimental hepatic fibrosis induced by carbon tetrachloride in rats World J Gastroenterol 28: 15: 1452-1458.

Ikeda K (1917) On the Taste of the Salt of Glutamic Acid, Proceedings of 8th International Congress of Applied Chemistry, 38: 147.

Jayanthi M, Raveendran R, Basu D (2009) Role of melatonin against oxidative tissue damage induced by Cleistanthus collinus in rat brain Indian $\mathrm{J}$ Med Res 130(4): 467-74. 
Kobayashi C, Kennedy LM, Hapern BP (2006) Experience-induced changes in taste identification of monosodium glutamate (MSG) are reversible. Chem Senses 31 (4): 301-306.

Koksal M, Kurcer Z, Erdogan D, Iraz M, Eren MA, Aydogan T, Ulas T (2012) Effect of melatonin and n-acetylcysteine on hepatic injury in rat induced by methanol intoxication: a comparative study. Eur Rev Med Pharmacol Sci 16(4): 437-44.

Leung AY, Foster S (2003) "Monosodium Glutamate". Encyclopedia of Common Natural Ingredients: Used in Food, Drugs, and Cosmetics (2nd Ed.). New York: Wiley: 373-375.

Malik VB, Ahluwalia P (1994) Studies on effect of monosodium glutamate (MSG) on various fractions of lipids and certain carbohydrate metabolic enzymes in liver and blood of adult male mice. Toxicol Lett 74(1): 69-77.

Mc Manus J, Mowry R (1963) Staining methods histological and histochemical. Harber and Row Inc. New York and London.

Messina SA, Dawson RJ (2000) Attenuation of Oxidative Damage to DNA by Taurine and Taurine Analogs. Adv Exp Med Biol 483: 355-67.

Mohareb ESR, Hamza AS (2001) Light and Electron Microscopic Studies on The Cytological and Cytochemical Effects of Food Additives on The Mammalian Liver. Master Thesis, Regional Center for Food \& Feed (RCFF). Accredited according to ISO/IEC 17025 from A2LA.

Nakanishi Y, Tsuneyama K, Fujimoto M, Salunga TL, Nomoto K, An JL, Takano Y, Iizuka S, Nagata M, Suzuki W, Shimada T, Aburada M, Nakano M, Selmi C, Gershwin ME (2008) Monosodium glutamate (MSG): A villain and promoter of liver inflammation and dysplasia. J Autoimmun 30 (1-2): 42-50.

Oforofuo IA, Onakewhor JU, Idaewor PE (1997) The Effect of chronic administration of msg on the histology of the adult Wistar rat testes. Bioscience Research Communications, Vo 9, 2.

Onakewhor, JU, Oforofuo IA, Singh SP (1998) Chronic Administration of Monosodium Glutamate Induces Oligozoospermia and Glycogen Accumulation in Wistar Rat Testes. Afri J Repro Health 2(2): 190197.

Pal S, Chatterjee AK (2006) Possible beneficial effects of melatonin supplementation on arsenic-induced oxidative stress in Wistar rats. Drug Chem Toxicol 29(4): 423-33.

Rao MV, Vyas, DD, Meda RB, Chawla SL (2011) In vitro protective role of melatonin against hemolysis induced by sodium fluoride in human red blood cells. Fluoride 44(2): 77-82.

Rozov SV, Filatova EV, Orlov AA, Volkova AV, Zhloba AR, Blashko EL, Pozdeyev NV (2003) N1-
acetyl-N2-formyl-5 methoxykynuramine is a product of melatonin oxidation in rats. J Pineal Res 35(4): 245-250.

Saad RA, EL-Babb MF, Shalaby AA (2013) Attenuation of acute and chronic liver injury by melatonin in rats. J Taibah Univ Sci 7(2): 88-96.

Salucci S, Burattini S, Battistelli M, Baldassarri V, Curzi D, Valmori A, Falcieri E (2014) Melatonin Prevents Chemical-Induced Haemopoietic Cell Death. Int J Mol Sci 15(4): 6625-40.

Samuels A (1999) The Toxicity/Safety of MSG: A Study in Suppression of Information," Accountability in Res 6(4): 259-310.

Sener-Muratoğlu G, Paskaloğlu K, Arbak S, Hürdağ C, Ayanoğlu-Dülger G (2001) Protective Effect of Famotidine, Omeprazole, And Melatonin Against Acetylsalicylic Acid-Induced Gastric Damage in Rats. Dig Dis Sci 46(2): 318-30.

Shi Z, Luscombe-Marsh ND, Wittert GA, Yuan B, Dai Y, Pan X, Taylor A (2010) Monosodium Glutamate is not associated with obesity or a greater prevalence of weight gain over 5 years: findings from the Jiangsu Nutrition Study. Br J Nutr 104(3): 457-463.

Tahan G, Akin H, Aydogan F, Ramadan SS, Yapicier O, Tarcin O, Uzun H, Tahan V, Zengin K (2010) Melatonin ameliorates liver fibrosis induced by bile-duct ligation in rats. Can J Surg 53(5): 313-8.

Tahan V, Atug O, Akin H (2009) Melatonin ameliorates methionine choline deficient diet induced nonalcoholic steatohepatitis in rats. J Pineal Res 46(4): 401-7.

Tahan V, Ozaras R, Canbakan B, Uzun H, Aydin S, Yildirim B, Aytekin H, Ozbay G, Mert A, Senturk $\mathrm{H}$ (2004) Melatonin reduces dimethylnitrosamineinduced liver fibrosis in rats. J Pineal Res 37: 7884.

Take G, Erdogan1 D, Helvacioglu1 F, Göktas1 G, Ozbey G, Uluoglu C, Yücel B, Guney Y, Hicsonmez A, Ozkan S (2009) Effect of melatonin and time of administration on irradiation-induced damage to rat testes. Braz J Med Biol Res 42(7): 621-628.

Tawfik MS, Al-Badr N (2012) Adverse Effects of Monosodium Glutamate on Liver and Kidney Functions in Adult Rats and Potential Protective Effect of Vitamins C and E. FNS 3: 651-659.

Waer HF, Edress E (2006) The Effect of Monosodium Glutamate (MSG) On Rat Liver and The Ameliorating Effect of "Guanidino Ethane Sulfonic acid (GES)" (Histological, Histochemical and Electron Microscopy Studies). The Egyp J Hosp Med 24: 524-538.

Walker R, Lupien JR (2000) The safety evaluation of Monosodium Glutamate J Nutr 30(4S): 1049S1052S. 
Wingenfeld P, Michalk DV, Sonntag A, Paas S, Minor T, Isselhard W (1996) Protective effect of taurine on hypoxia and reoxygenation-induced damage of human colon cells (HT 29). Adv Exp Med Biol 403: 213-22.

Yenilmez A, Isikli B, Aral E, Degirmenci I, Sutken E, Baycu C (2010) Antioxidant Effects of Melatonin and Coenzyme Q10 on Oxidative Damage Caused by Single-Dose Ochratoxin A in Rat Kidney. Chin J Physiol 53(5): 310-317.

You JS, Chang KJ (1998) Taurine protects the liver against lipid peroxidation and membrane disintegration during rat hepatocarcinogenesis. Adv Exp Med Biol 442:105-12.

Yu T, Zhao Y, Shi W, Ma R, Yu L (1997) Effects of maternal oral administration of monosodium glutamate at a late stage of pregnancy on developing mouse fetal brain. Brain Res 747: 195-206.

Zhou BF, Stamler J, Dennis B, Moag-Stahlberg A, Okuda N, Robertson C, Zhao L, Chan Q, Elliott P (2003) Nutrient intakes of middle-aged men and women in China, Japan, United Kingdom, and United States in the late 1990s: the INTERMAP study. J Hum Hypertens 17(9): 623-30. 